Supplementary Material

\title{
Micropollutant Mass Transfer Zones in Granular Activated Carbon Contactors
}

Jie Yuan ${ }^{1}$, Armin Safari ${ }^{1}$, Paul Lugo ${ }^{1,2}$, Laura Alvarez ${ }^{1}$, Ronald Hofmann ${ }^{1}$

${ }^{1}$ Drinking water research group, Department of Civil \& Mineral Engineering, University of Toronto, Toronto, Ontario, M5S 1A4

${ }^{2}$ Instituto Tecnológico y de Estudios Superiores de Monterrey, Av. Eugenio Garza Sada 2501 Sur, Tecnológico, 64849 Monterrey, N.L., Mexico

\section{Summary}

24 Pages including 10 figures and 8 tables 
Table S1. GAC samples used in the tests

\begin{tabular}{|c|c|c|c|c|}
\hline & Plant A & Plant B & Plant C & Plant D \\
\hline GAC type & Filtrasorb $^{\circledR} 300$ & Filtrasorb $^{\circledR} 300$ & Filtrasorb $^{\circledR} 300$ & Filtrasorb $^{\circledR} 300$ \\
\hline Material & $\begin{array}{l}\text { Bituminous } \\
\text { coal-based }\end{array}$ & $\begin{array}{l}\text { Bituminous } \\
\text { coal-based }\end{array}$ & $\begin{array}{l}\text { Bituminous } \\
\text { coal-based }\end{array}$ & $\begin{array}{l}\text { Bituminous } \\
\text { coal-based }\end{array}$ \\
\hline Effective size $(\mathrm{mm})^{\mathrm{a}}$ & $0.8-1.0$ & $0.8-1.0$ & 0.8-1.0 & $0.8-1.0$ \\
\hline Iodine number $(\mathrm{mg} / \mathrm{g})^{a}$ & 900 & 900 & 900 & 900 \\
\hline $\begin{array}{c}\text { Source water TOC value }{ }^{b} \\
(\mathrm{mg}-\mathrm{C} / \mathrm{L})\end{array}$ & 5.5 & 3.3 & 6.0 & 2.4 \\
\hline GAC contactor depth (m) & 0.75 & 0.8 & 1.8 & 0.75 \\
\hline EBCT tested ${ }^{\mathrm{c}}(\mathrm{min})$ & 10 & 1,15 & 12 & 4 \\
\hline Apparent density ${ }^{\mathrm{d}}\left(\mathrm{g} / \mathrm{cm}^{3}\right)$ & 0.58 & 0.51 & 0.53 & 0.56 \\
\hline Service time & 3 years & $\begin{array}{l}1 \text { week, } 3 \text { weeks, } \\
7 \text { weeks, } 4 \text { years }\end{array}$ & 17 years & $\begin{array}{l}1 \text { year, } 3 \text { years, } \\
4 \text { years, } 6 \text { years }\end{array}$ \\
\hline
\end{tabular}

${ }^{a}$ Virgin GAC specifications provided by the manufacturer

$\mathrm{b}$ Total organic carbon

${ }^{\mathrm{c}}$ Empty bed contact time

${ }^{\mathrm{d}}$ Measured at the University of Toronto lab

e Service time was the operation time documented by calendar date, including idle periods 
2. Properties of selected compounds

Table S2. Properties of selected compounds in this study

\begin{tabular}{|c|c|c|c|c|c|}
\hline $\begin{array}{c}\text { Chemical } \\
\text { group }\end{array}$ & Compound & Chemical structure & $\mathbf{p K}_{\mathrm{a}}{ }^{\mathrm{a}}$ & $\operatorname{LogK}_{0 w}{ }^{b}$ & BIOWIN6 $^{\mathrm{c}}$ \\
\hline \multirow[t]{2}{*}{$\begin{array}{l}\text { Taste and odour } \\
\text { compounds }\end{array}$} & Geosmin & & $\mathrm{N} / \mathrm{A}^{\mathrm{d}}$ & 3.85 & 0.41 \\
\hline & $\begin{array}{l}\text { 2-Methylisoborneol } \\
\text { (MIB) }\end{array}$ & & $\mathrm{N} / \mathrm{A}^{\mathrm{d}}$ & 3.25 & 0.38 \\
\hline $\begin{array}{l}\text { Artificial } \\
\text { sweetener }\end{array}$ & Sucralose & $\mathrm{HO}_{\mathrm{Cl}}$ & 12.52 & 0.68 & 0.0040 \\
\hline Stimulant & Caffeine & & 10.40 & -0.13 & 0.66 \\
\hline \multirow[t]{2}{*}{ Pharmaceuticals } & Carbamazepine & & 13.90 & 3.28 & 0.036 \\
\hline & Acetaminophen & & 9.38 & 0.34 & 0.51 \\
\hline
\end{tabular}

${ }^{a}$ Howard and Meylan (1997), ${ }^{\mathrm{b}}$ ACD/Labs Percepta Platform (2020), ${ }^{\mathrm{c}}$ The probability of rapid aerobic biodegradation estimated using EPI SuiteTM BIOWIN v4.10, MITI nonlinear model, ${ }^{\mathrm{d}}$ no data. 
3. Text S1. Sieve method, GAC size distribution, and minicolumn test setup

Each GAC sample (i.e., top, middle, and bottom) was sieved using the U.S. standard sieve test to obtain the representative fraction for the minicolumn test. Air-dried GAC was obtained by drying the wet GAC at room temperature for $24 \mathrm{~h}$. The sieve analysis was conducted according to the following procedures:

1) A whole depth of GAC core sample was collected using a core sampler, and it was equally divided to three segments according to filter depth: top, middle, and bottom. An additional sample was obtained by mixing the same amount of GAC from each layer. Four types of GAC samples were stored wet at $4{ }^{\circ} \mathrm{C}$ in the dark before use.

2) GAC samples were dried in air at room temperature prior to sieve analysis.

3) Sieves $(\# 8, \# 10, \# 12, \# 14, \# 16, \# 18, \# 20$, and \#25) were weighed and staked in order of sieve size. Table S1shows the particle size for each sieve level.

4) Each type of GAC sample was put into the first layer of the sieve, and sieves were placed on a shaker and shaken for $6 \mathrm{~min}$.

5) After shaking was complete, each sieve was weighed to determine the GAC weight in each sieve.

The particle size distribution of 6-year-old Plant D GAC is shown in Figure S1. As a result, there was particle size stratification according to filter depth, with the top layer containing more smaller size particles. However, the difference is not significant. The representative size of air dried GAC from all layers was determined to be $10 \times 12$ mesh size $(1.7-2.0 \mathrm{~mm})$. 


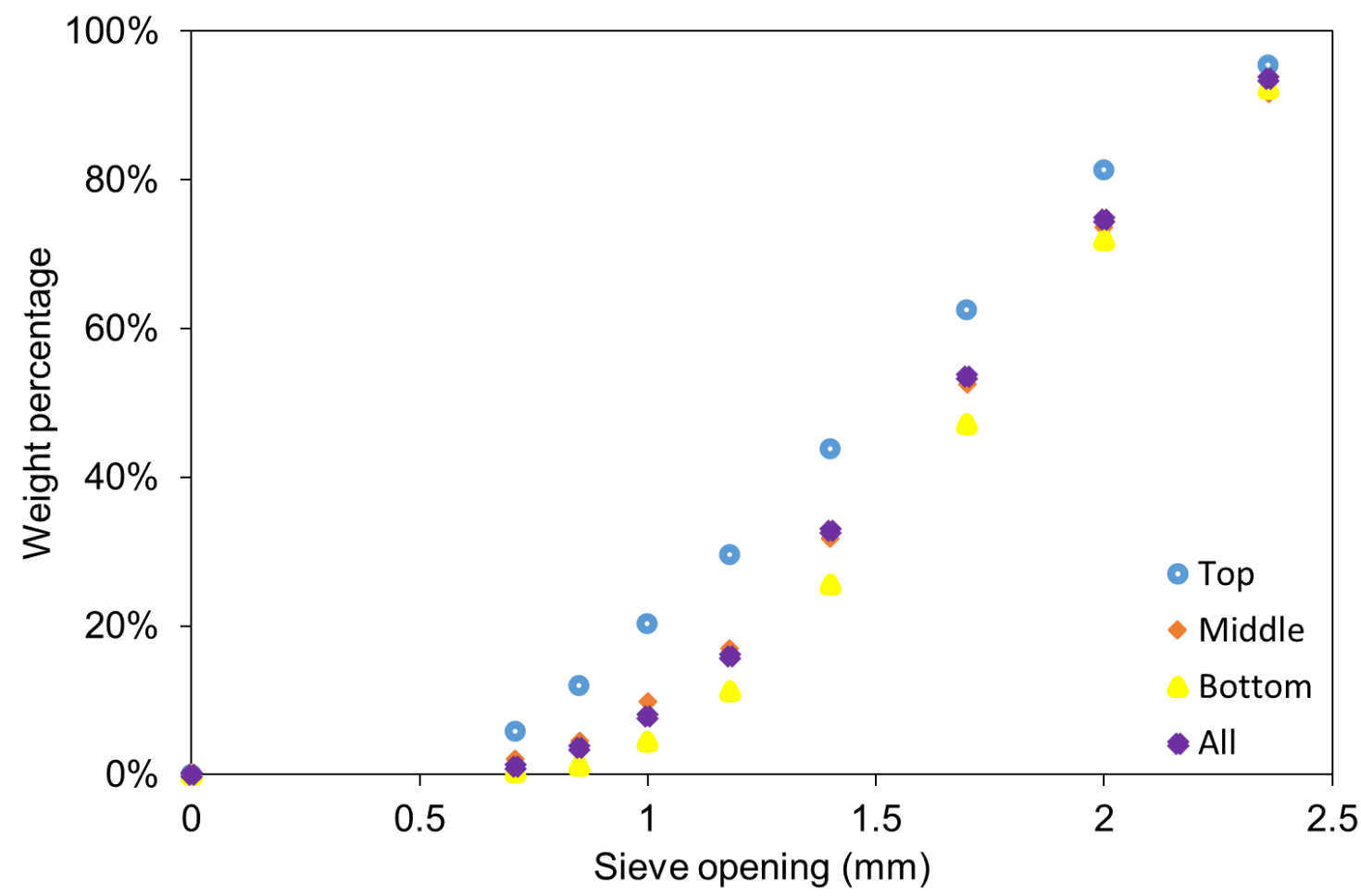

Figure S1. An example of particle size distribution of 6-year-old Plant D GAC

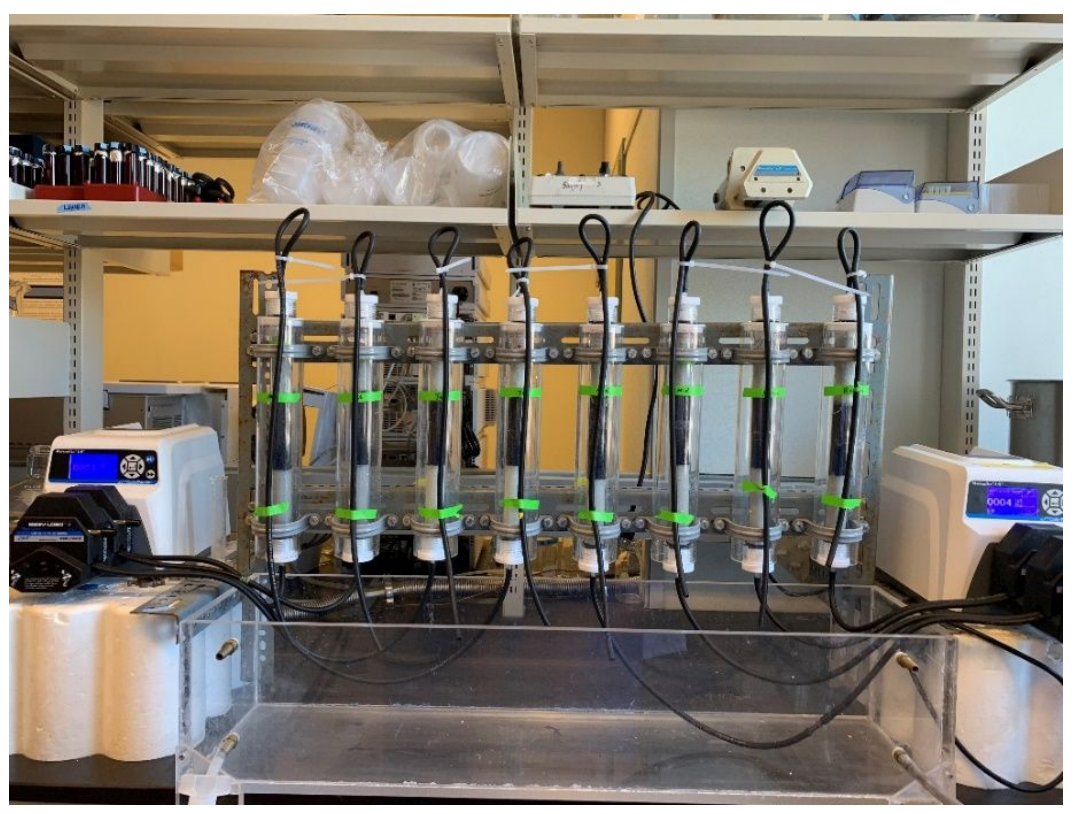

Figure S2. Minicolumn test setup

4. Text S2. Confirmation of a lack of competitive adsorption between the selected 
micropollutants

Previous studies have confirmed that there was no competitive adsorption between geosmin and MIB at ng/L levels (Huang et al., 2019). Thus, the focus here is to confirm there is no competitive adsorption between caffeine, sucralose, carbamazepine, or acetaminophen and geosmin/MIB, and the results are shown in Figure S3 and Figure S4.

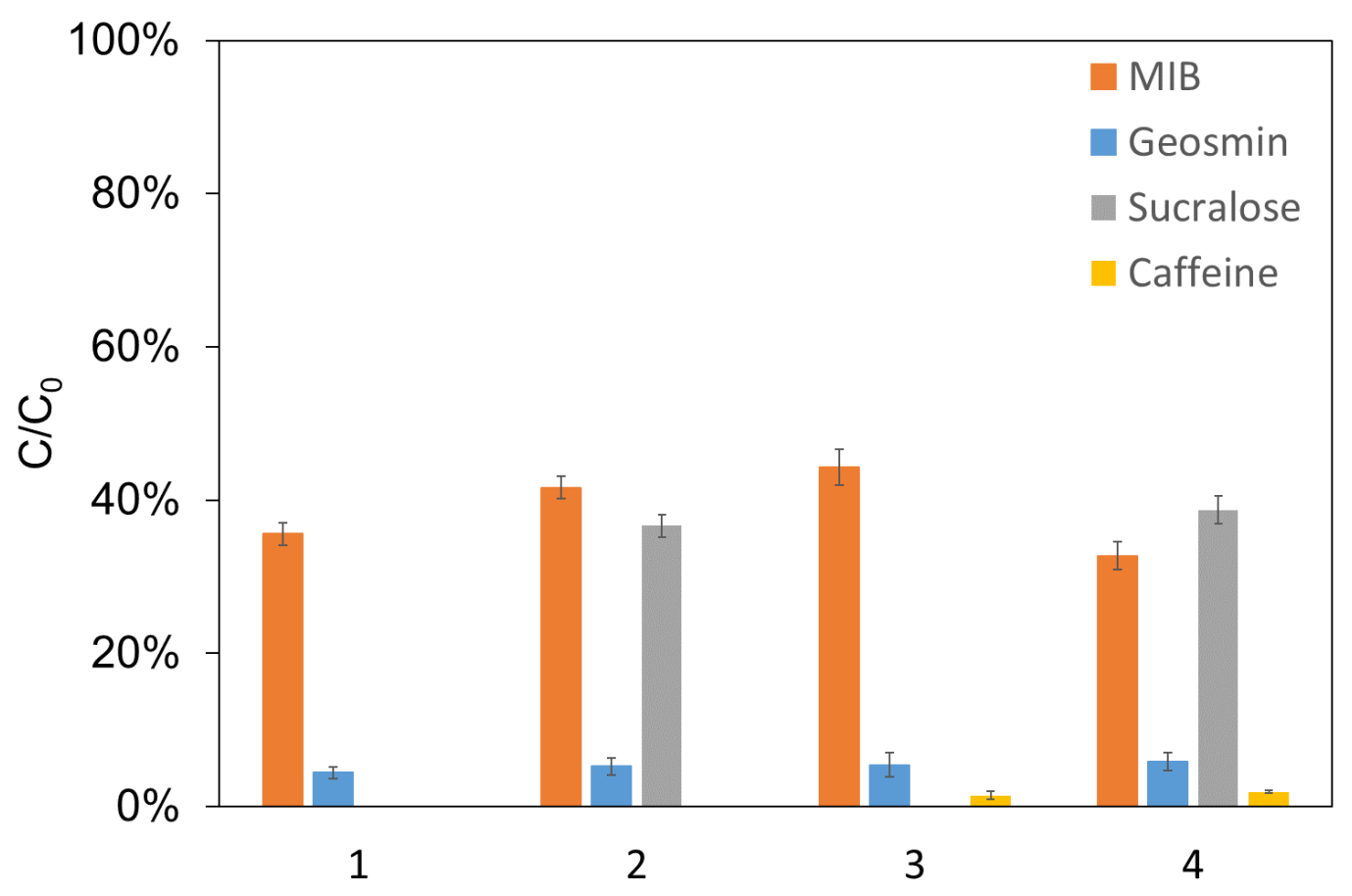

Figure S3. Comparison of the results of the minicolumn tests. Test 1 spiked with geosmin and MIB; Test 2 spiked with geosmin, MIB, and sucralose; Test 3 spiked with geosmin, MIB, and caffeine; Test 4 spiked with geosmin, MIB, sucralose, and caffeine. 


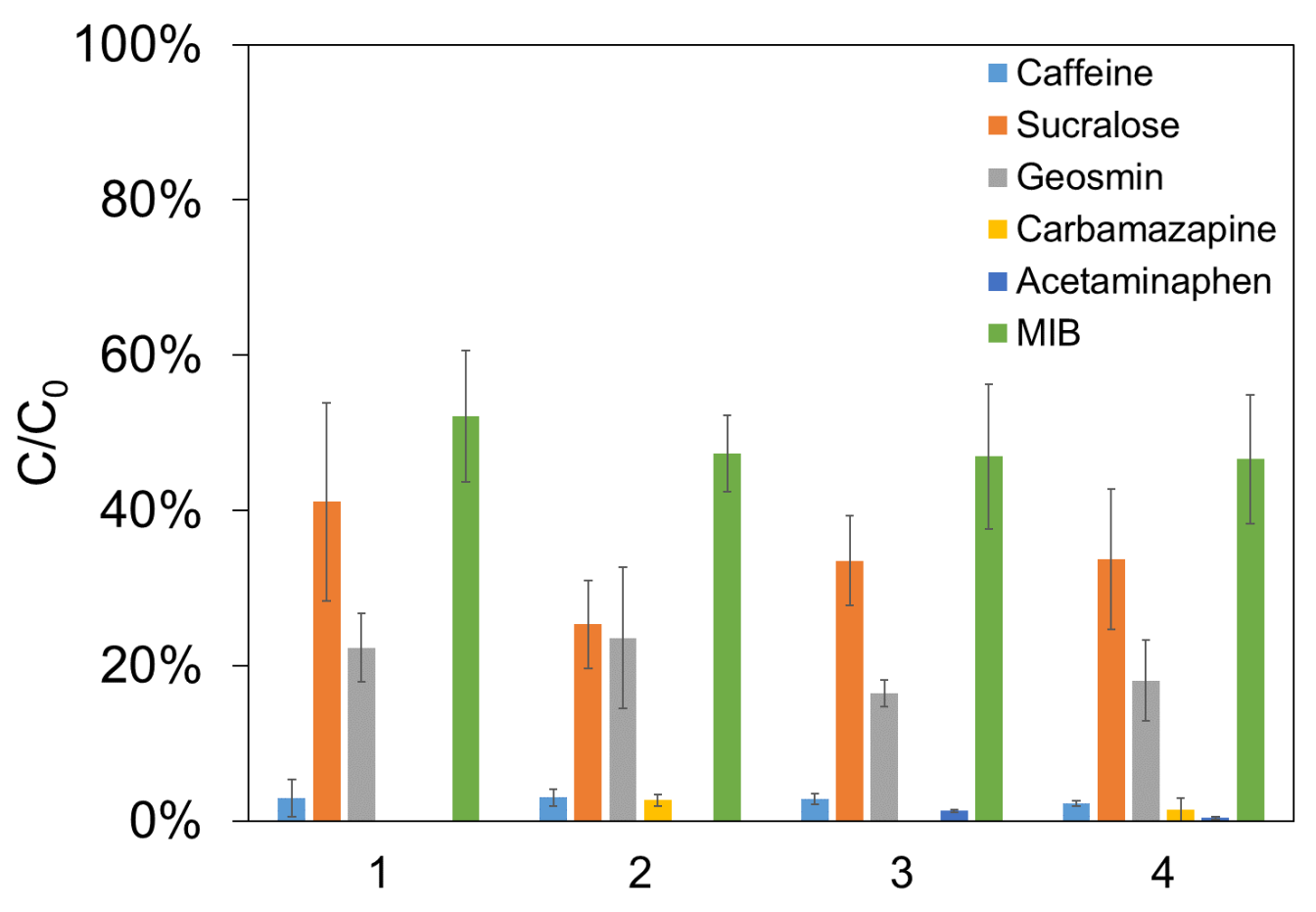

Figure S4. Comparison of the results of the minicolumn tests. Test 1 spiked with MIB, geosmin, caffeine, and sucralose; Test 2 spiked with MIB, geosmin, caffeine, sucralose, and carbamazepine; Test 3 spiked with MIB, geosmin, caffeine, sucralose, and acetaminophen; Test 4 spiked with MIB, geosmin, caffeine, sucralose, carbamazepine, and acetaminophen. 
Table S3. Characteristics of feedwater for the tests

\begin{tabular}{|c|c|c|c|c|}
\hline Parameters & Plant A & Plant B & Plant C & Plant D \\
\hline $\mathrm{TOC}(\mathrm{mg} / \mathrm{L})$ & 5.5 & 3.3 & 6.0 & 2.4 \\
\hline $\mathrm{UV}_{254}$ & 0.058 & 0.025 & 0.052 & 0.026 \\
\hline $\mathrm{pH}$ & 7.76 & 7.64 & 7.68 & 7.57 \\
\hline Turbidity (NTU) & 0.32 & 0.40 & 0.29 & 0.30 \\
\hline Alkalinity $\left(\mathrm{mg} \mathrm{CaCO}_{3} / \mathrm{L}\right)$ & 113 & 94 & 110 & 90.4 \\
\hline Residual total chlorine $(\mathrm{mg} / \mathrm{L})$ & 0.04 & 0.01 & 0.03 & 0.02 \\
\hline
\end{tabular}

5. Text S3. Detailed description of parallel minicolumn test three phase conditions

The conditions of each test are shown in Table S4. This study had three phases: in Phase 1 (Tests 1 to 3), the test was conducted by using GAC collected from Plants A-C, respectively, in which all six micropollutants were spiked together into the feed water. Phase 1 was to understand the MTZ shape for micropollutants in full-scale GAC contactors. In Phase 2 (Tests 4-7), four different ages of GAC harvested from Plant D were used. In Phase 3 (Tests 8-10), GAC was harvested from a newly-installed filter in Plant B after 1, 3, and 7 weeks of operation, to observe the possible evolution of the MTZ in new GAC. For both Phase 2 and Phase 3, only MIB and geosmin were used as the target compounds, with the focus of these particular tests to evaluate the effect of preloading time on GAC performance across the bed depth. Since new GAC was used in Test 8-10, the EBCT was set to 1 min instead of the full-scale EBCT (15 min) to ensure that there would be a measurable contaminant breakthrough in the effluent. 
Table S4. Experimental conditions of each minicolumn layer test

\begin{tabular}{|c|c|c|c|c|}
\hline \multicolumn{2}{|c|}{ Test } & Target compounds & GAC age and size & $\begin{array}{l}\text { EBCT } \\
(\min )\end{array}$ \\
\hline \multirow[t]{3}{*}{$\begin{array}{l}\text { Phase } \\
1\end{array}$} & 1 & $\begin{array}{l}\text { MIB }{ }^{\mathrm{a}} \text {, sucralose }{ }^{\mathrm{b}}, \text { carbamazepine }^{\mathrm{b}}, \\
\text { geosmin }^{\mathrm{a}}, \text { caffeine }^{\mathrm{b}}, \text { acetaminophen }^{\mathrm{b}}\end{array}$ & $\begin{array}{l}\text { 3-year-old Plant A GAC (GAC 1) } \\
\text { Top: 1.7-2.0 mm, Middle: } 1.7-2.0 \mathrm{~mm} \text {, } \\
\text { Bottom: } 1.7-2.0 \mathrm{~mm}\end{array}$ & 10 \\
\hline & 2 & $\begin{array}{l}\text { MIB, sucralose, carbamazepine, } \\
\text { geosmin, caffeine, acetaminophen }\end{array}$ & $\begin{array}{l}\text { 4-year-old Plant B GAC (GAC 2) } \\
\text { Top: 1.7-2.0 mm, Middle: } 1.7-2.0 \mathrm{~mm} \text {, } \\
\text { Bottom: } 1.7-2.0 \mathrm{~mm}\end{array}$ & 15 \\
\hline & 3 & $\begin{array}{l}\text { MIB, sucralose, carbamazepine, } \\
\text { geosmin, caffeine, acetaminophen }\end{array}$ & $\begin{array}{l}\text { 17-year-old Plant C GAC (GAC } 3 \text { ) } \\
\text { Top: } 1.4-2.0 \mathrm{~mm} \text {, Middle: } 1.4-2.0 \mathrm{~mm} \text {, } \\
\text { Bottom: } 1.4-2.0 \mathrm{~mm}\end{array}$ & 12 \\
\hline \multirow[t]{4}{*}{$\begin{array}{c}\text { Phase } \\
2\end{array}$} & 4 & MIB, geosmin & $\begin{array}{l}\text { 1-year-old Plant D GAC (GAC 4) } \\
\text { Top: } 1.4-2.0 \mathrm{~mm} \text {, Middle: } 1.4-2.0 \mathrm{~mm} \text {, } \\
\text { Bottom: } 1.4-2.0 \mathrm{~mm}\end{array}$ & 4 \\
\hline & 5 & MIB, geosmin & $\begin{array}{l}\text { 3-year-old Plant D GAC (GAC 5) } \\
\text { Top: } 1.4-2.0 \mathrm{~mm} \text {, Middle: } 1.4-2.0 \mathrm{~mm} \text {, } \\
\text { Bottom: } 1.4-2.0 \mathrm{~mm}\end{array}$ & 4 \\
\hline & 6 & MIB, geosmin & $\begin{array}{l}\text { 5-year-old Plant D GAC (GAC 6) } \\
\text { Top: } 1.4-2.0 \mathrm{~mm} \text {, Middle: } 1.4-2.0 \mathrm{~mm} \text {, } \\
\text { Bottom: } 1.4-2.0 \mathrm{~mm}\end{array}$ & 4 \\
\hline & 7 & MIB, geosmin & $\begin{array}{l}\text { 6-year-old Plant D GAC (GAC 7) } \\
\text { Top: 1.4-2.0 mm, Middle: } 1.4-2.0 \mathrm{~mm} \text {, } \\
\text { Bottom: } 1.4-2.0 \mathrm{~mm}\end{array}$ & 4 \\
\hline \multirow[t]{3}{*}{$\begin{array}{c}\text { Phase } \\
3\end{array}$} & 8 & MIB, geosmin & $\begin{array}{l}\text { 1-week-old Plant B GAC (GAC 8) } \\
\text { Top: } 1.7-2.0 \mathrm{~mm} \text {, Middle: } 1.7-2.0 \mathrm{~mm} \text {, } \\
\text { Bottom: } 1.7-2.0 \mathrm{~mm}\end{array}$ & 1 \\
\hline & 9 & MIB, geosmin & $\begin{array}{l}\text { 3-week-old Plant B GAC (GAC 9) } \\
\text { Top: 1.7-2.0 mm, Middle: } 1.7-2.0 \mathrm{~mm} \text {, } \\
\text { Bottom: } 1.7-2.0 \mathrm{~mm}\end{array}$ & 1 \\
\hline & 10 & MIB, geosmin & $\begin{array}{l}\text { 7-week-old Plant B GAC (GAC 10) } \\
\text { Top: 1.7-2.0 mm, Middle: } 1.7-2.0 \mathrm{~mm} \text {, } \\
\text { Bottom: } 1.7-2.0 \mathrm{~mm}\end{array}$ & 1 \\
\hline
\end{tabular}

${ }^{\mathrm{a}}$ spike concentration is $100 \mathrm{ng} / \mathrm{L},{ }^{\mathrm{b}}$ spike concentration is $50 \mu \mathrm{g} / \mathrm{L}$ 
6. Text S4. Batch kinetic test to determine MIB/geosmin adsorption equilibrium time A preliminary test was conducted to determine the minimum time at $20^{\circ} \mathrm{C}$ to achieve adsorption equilibrium. The batch kinetic test was conducted using five $250 \mathrm{~mL}$ amber bottles. Each bottle was dosed with $128 \mathrm{mg}$ of the 4-year-old Plant B GAC samples. The bottles were filled headspace free with GAC contactor influent water spiked with $300 \mathrm{mg} / \mathrm{L}$ sodium azide to suppress microbial activity. Geosmin and 2-methylisoborneol (MIB) were added to the water to an approximately initial concentration of $200 \mathrm{ng} / \mathrm{L}$. Then, all the bottles were tightly sealed with Teflon lined caps and tumbled for 65 days. The change of the T\&O compound concentrations was monitored by sacrificially sampling each bottle at a predetermined time interval (i.e., 0 day, 21 days, 35 days, 50 days and 65 days). The water was filtered through a $0.45 \mu \mathrm{m}$ membrane to remove the GAC for analysis.

Figure S5 shows the concentration change in the experiment. It can be seen that there was insignificant concentration variation after 35 days for geosmin and MIB. It is reasonable to conclude that at least 35 days is required to achieve the adsorption equilibrium for geosmin and MIB. 


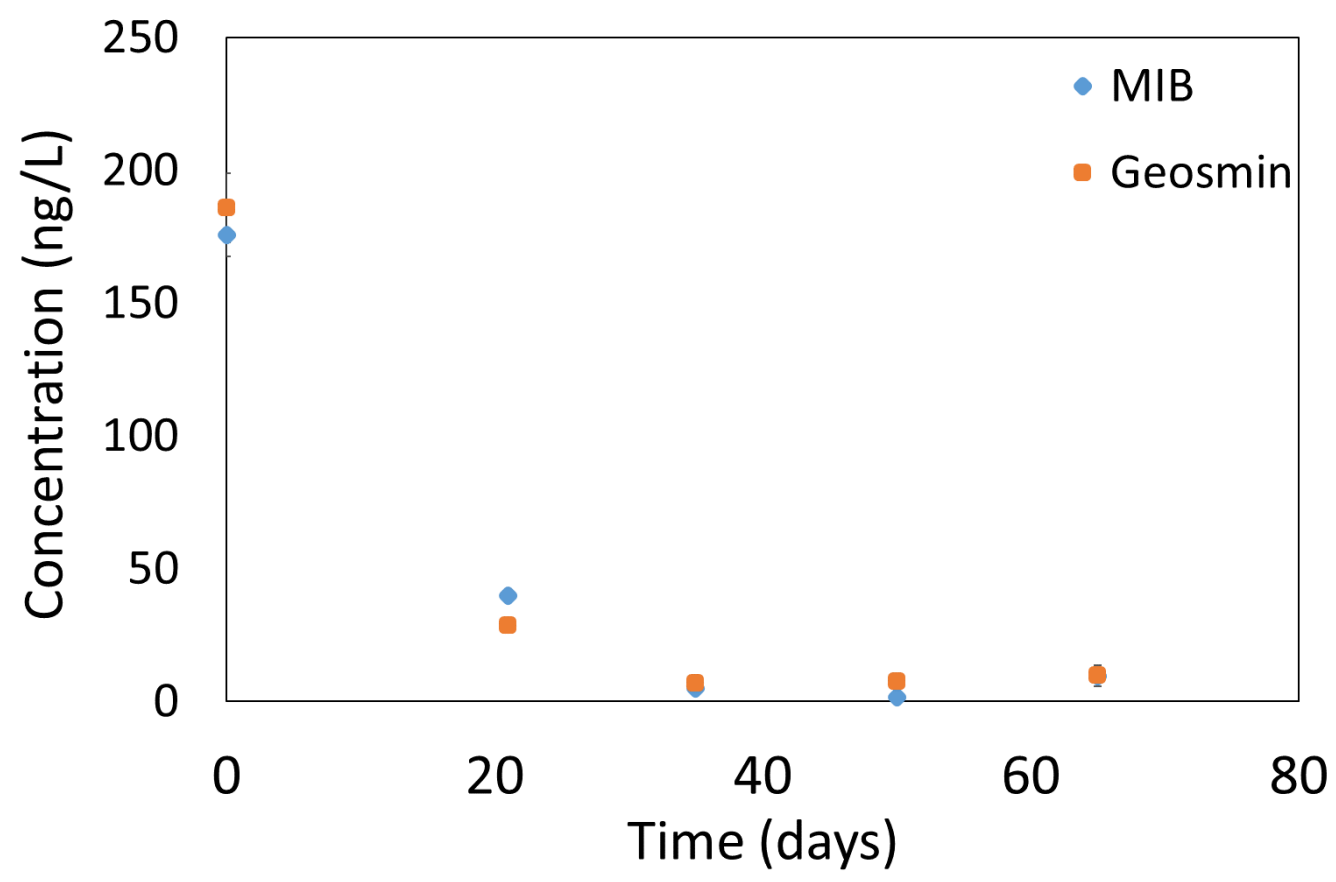

Figure S5. The change of geosmin and MIB concentrations during the test

\section{Text S5. Calculation of MTZ length.}

During initial GAC operation, the velocity of the adsorption front moving through the bed increases with depth, thus spreading the MTZ (Smith, 1997). As operation time increases, the further mass transfer and attachment of adsorbates in GAC mitigate the uneven movement of the front, which enables formation of a constant MTZ pattern (Vagliasindi and Hendricks, 1992). The minimum EBCT that is required to achieve a constant MTZ pattern for MIB and geosmin can be calculated by Eq. (S1), which is valid when Freundlich isotherm parameter 1/n is less than 1. Eq. (S1) is derived based on the homogeneous surface diffusion model (HSDM) calculation (Hand et al., 1984).

$$
E B C T_{\min }=\frac{R_{p} \cdot S t_{\text {min }}}{60 K_{f}(1-\epsilon)}=\frac{R_{p}\left(A_{0} B i+A_{1}\right)}{60 K_{f}(1-\epsilon)}
$$


where $E B C T_{\min }$ is the minimum EBCT required to achieve a constant MTZ pattern (min), $R_{p}$ is the GAC particle radius $(\mathrm{cm}), S t_{\min }$ is the minimum Stanton number (dimensionless) required to achieve a constant MTZ pattern, $A_{0}$ and $A_{1}$ are the constants (dimensionless) to calculate $S t_{\text {min }}$, which are given in Table S5 depending on the values of $B i$ and $1 / \mathrm{n}$ (Hand et al., 1984), $B i$ is the Biot number (dimensionless) defined by Eq. (S2), 1/n is Freundlich isotherm intensity constant for the target compound with the presence of NOM, which is determined using the ideal adsorbed solution theory (IAST)-equivalent background compound (EBC) approach coupled with the multi-component Freundlich isotherm, $K_{f}$ is film diffusion coefficient $(\mathrm{cm} / \mathrm{s})$, which can be determined by fitting the experimental result to the HSDM with the detailed procedure presented by Yuan et al. (2020), and $\epsilon$ is the bed void fraction.

$$
B i=\frac{K_{f} R_{p}(1-\epsilon)}{D_{s} D_{g} \epsilon}
$$

where $D_{s}$ is the surface diffusion coefficient $\left(\mathrm{cm}^{2} / \mathrm{s}\right)$, which can be determined using an empirical equation (Eq. (S3)) (Sontheimer et al., 1988), $D_{g}$ is the solute distribution parameter (dimensionless) defined by Eq. (S4).

$$
\begin{gathered}
D_{s}=\frac{D_{l} \epsilon_{a} C_{0}}{\tau_{p} \rho_{a} q_{0}} \times S P D F R \\
D_{g}=\frac{\rho_{a} q_{0}(1-\epsilon)}{\epsilon C_{0}}
\end{gathered}
$$

where $D_{l}$ is the liquid diffusivity $\left(\mathrm{cm}^{2} / \mathrm{s}\right)$, which can be estimated by the Hayduk and Laudie correlation (Eq. (S5)) (Hayduk and Laudie, 1974), $\epsilon_{a}$ is GAC particle porosity (dimensionless), 
$C_{0}$ is the influent concentration of the adsorbate $(\mathrm{mg} / \mathrm{L}), \tau_{p}$ is the adsorbent tortuosity (dimensionless), which can be calculated based on Eq. (S6) (Sontheimer et al., 1988), $\rho_{a}$ is GAC particle density $\left(\mathrm{kg} / \mathrm{m}^{3}\right), q_{0}$ is the solid phase loading in equilibrium with $C_{0}(\mathrm{mg} / \mathrm{g})$, and $S P D F R$ is the surface to the pore diffusion flux ratio (dimensionless), which is set to 6.58 for GAC without significant NOM fouling (Crittenden et al., 1987). This scenario applies to our study since several-week-old GAC was used in the experiment.

$$
\begin{gathered}
D_{l}=\frac{13.26 \times 10^{-5}}{\mu_{l}^{1.14} V_{b}^{0.589}} \\
\tau_{p}=0.334+6.61 \times 10^{-6} \times t_{s}
\end{gathered}
$$

where $\mu_{l}$ is the water viscosity $(\mathrm{cP}), V_{b}$ is the molar volume of the adsorbate at its normal boiling point $\left(\mathrm{cm}^{3} / \mathrm{mol}\right)$, and $t_{s}$ is the service time (min). In this study, values of $\tau_{p}=0.40,0.53$ and 0.80 were selected, representing approximately 1-week-old, 3-week-old, and 7-week-old GAC, respectively.

The EBCT of the MTZ is calculated based on the elapsed time for an appropriate concentration range (Eq. (S7)) (Hand et al., 1984). The upstream concentration value of 0.95 was chosen, meaning that at least $95 \%$ of GAC capacity has been used after the adsorption wave front has passed. The downstream end of the MTZ was set to be 0.10 to indicate that the treatment objective is $10 \%$ of the influent concentration. This selection is because the odour threshold concentration of geosmin and MIB is approximately $10 \mathrm{ng} / \mathrm{L}$ (Young et al., 1996), which is $10 \%$ of the spiked feed water concentration $(100 \mathrm{ng} / \mathrm{L})$ for the column test. 


$$
E B C T_{M T Z}=\left[T\left(\frac{C}{C_{0}}=0.95\right)-T\left(\frac{C}{C_{0}}=0.10\right)\right] E B C T_{\text {min }}
$$

where $T$ is the throughput to achieve $\frac{C}{C_{0}}$ (dimensionless), which can be calculated using an empirical equation (Eq. (S8)) (Hand et al., 1984).

$$
T\left(\frac{C}{C_{0}}\right)=B_{0}+B_{1}\left(\frac{C}{C_{0}}\right)^{B_{2}}+\frac{B_{3}}{1.01-\left(\frac{C}{C_{0}}\right)^{B_{4}}}
$$

where $B_{0}, B_{1}, B_{2}, B_{3}$, and $B_{4}$ are constants (dimensionless) to calculate $T\left(\frac{C}{C_{0}}\right)$, which are given in Table S6 depending on the values of $B i$ and 1/n (Hand et al., 1984).

Table S5. Minimum Stanton number required to achieve constant pattern conditions as

\begin{tabular}{|c|c|c|c|c|}
\hline \multirow{3}{*}{$\begin{array}{c}\text { Freundlich } \\
\text { isotherm } \\
\text { parameter } 1 / \mathbf{n}\end{array}$} & \multicolumn{4}{|c|}{ Empirical equation $S t_{\min }=A_{0} B i+A_{1}$} \\
\hline & \multicolumn{2}{|c|}{$0.5 \leq B i \leq 10$} & \multicolumn{2}{|c|}{$10 \leq B i \leq \infty$} \\
\hline & $A_{0}$ & $A_{1}$ & $A_{0}$ & $A_{1}$ \\
\hline 0.05 & $2.11 \times 10^{-2}$ & 1.989 & 0.22 & - \\
\hline 0.10 & $2.11 \times 10^{-2}$ & 2.189 & 0.24 & - \\
\hline 0.20 & $4.21 \times 10^{-2}$ & 2.379 & 0.28 & - \\
\hline 0.30 & $1.05 \times 10^{-1}$ & 2.547 & 0.36 & - \\
\hline 0.40 & $2.32 \times 10^{-1}$ & 2.684 & 0.50 & - \\
\hline 0.50 & $5.26 \times 10^{-1}$ & 2.737 & 0.80 & - \\
\hline 0.60 & $1.16 \times 10^{0}$ & 3.421 & 1.50 & - \\
\hline 0.70 & $1.79 \times 10^{0}$ & 7.105 & 2.50 & - \\
\hline 0.80 & $3.68 \times 10^{0}$ & 13.160 & 5.00 & - \\
\hline 0.90 & $6.32 \times 10^{0}$ & 56.842 & 12.00 & - \\
\hline
\end{tabular}
function of $\mathrm{Bi}$ for various $1 / \mathrm{n}$ values (adapted from Hand et al. (1984)). 
Table S6. Parameters used for the empirical equation to calculate T (adapted from Hand et al. (1984))

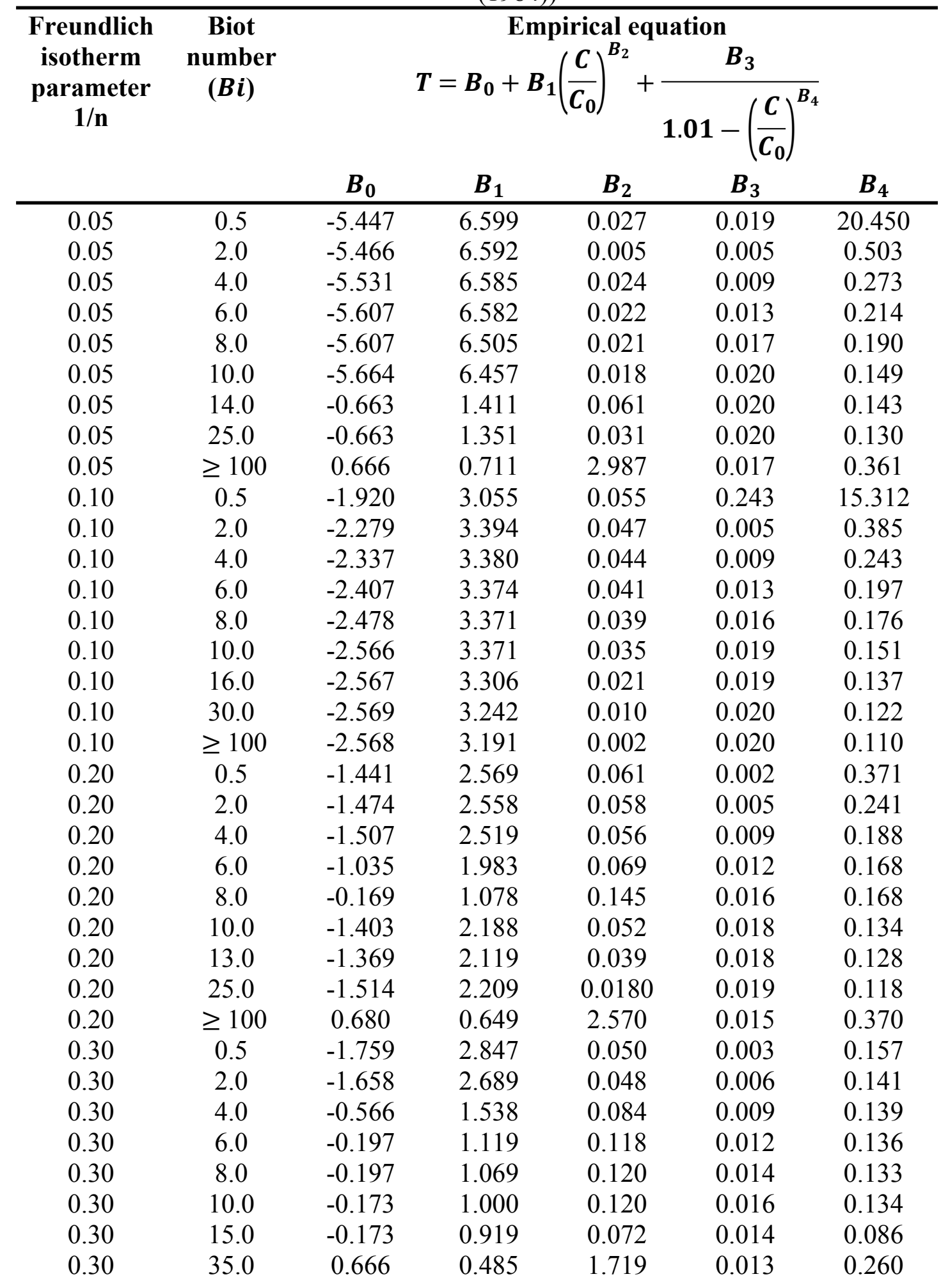




\begin{tabular}{ccccccc}
0.30 & $\geq 100$ & 0.696 & 0.517 & 2.055 & 0.013 & 0.303 \\
0.40 & 0.5 & -0.534 & 1.604 & 0.094 & 0.004 & 0.138 \\
0.40 & 2.0 & -0.166 & 1.191 & 0.122 & 0.006 & 0.134 \\
\hline
\end{tabular}

Table S6. Parameters used for the empirical equation to calculate T (adapted from Hand et al.

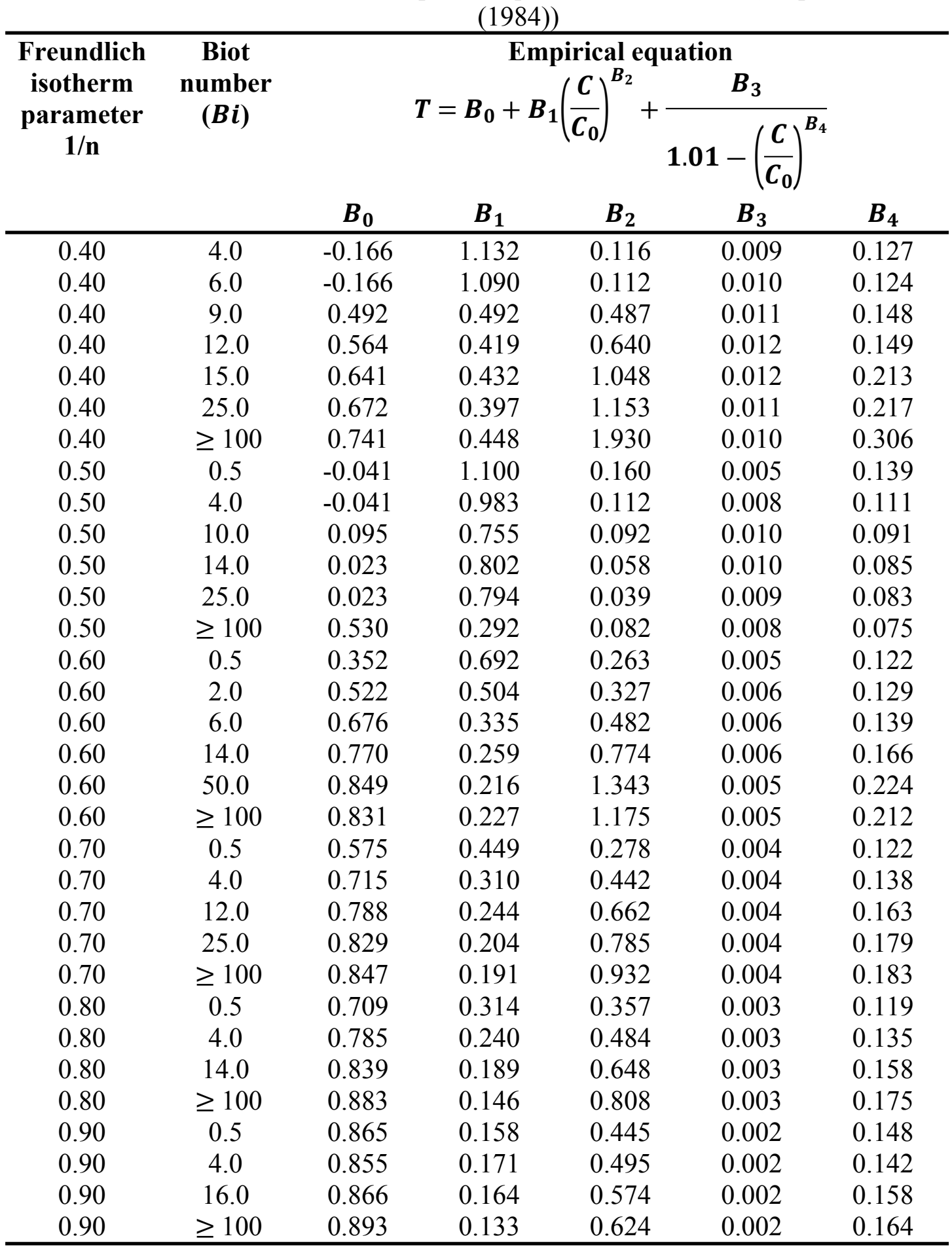


Table S7. The MTZ lengths of MIB and geosmin at different GAC preloading times

\begin{tabular}{cccccc}
\hline Compounds & Preloading time & $\boldsymbol{D}_{\boldsymbol{g}}{ }^{\mathrm{a}}$ & $\boldsymbol{B}_{\boldsymbol{i}}{ }^{\mathrm{b}}$ & $\boldsymbol{E B C} \boldsymbol{T}_{\boldsymbol{m i n}^{\mathrm{c}}}{ }^{(\mathbf{m i n})}$ & $\boldsymbol{E B C} \boldsymbol{T}_{\boldsymbol{M T Z}}{ }^{\mathrm{d}}(\mathbf{m i n})$ \\
\hline \multirow{2}{*}{ MIB } & 1 week & 78411 & 11.12 & 2.31 & 2.87 \\
& 3 weeks & 45835 & 13.10 & 5.46 & 5.20 \\
& 7 weeks & 28065 & 16.77 & 26.20 & 27.12 \\
\hline \multirow{2}{*}{ Geosmin } & 1 week & 61404 & 14.10 & 2.39 & 2.87 \\
& 3 weeks & 37193 & 16.84 & 4.27 & 3.91 \\
& 7 weeks & 27432 & 24.60 & 25.63 & 26.53 \\
\hline
\end{tabular}

${ }^{a}$ solute distribution parameter (determined by Eq. (S4)). ${ }^{\mathrm{b}}$ Biot number (determined by Eq. (S2)). ${ }^{c}$ the minimum EBCT required to achieve a constant MTZ pattern (min) (determined by Eq. (S1)). ${ }^{d}$ the EBCT of the MTZ, and its calculation is based on the bottom GAC isotherm to give a conservative estimate.

\section{Text S6. Q-Q plots}

A Q-Q plot is a probability plot that can compare the probability distributions of two data sets by plotting their quantiles against each other. The Q-Q plot can be conducted by the following procedure:

Step 1: Place the number from the smallest to the largest, and label these points $\mathrm{X}_{1}, \mathrm{X}_{2}, \ldots$, $\mathrm{X}_{\mathrm{i}}, \ldots, \mathrm{X}_{\mathrm{n}}$. Take the breakthrough mean of the minicolumn tests using 1-year-old Plant A GAC for example:

$0.202,0.130,0.183,0.172$ 
Step 2: Calculate the corresponding expected value of the order statistic for each data based on their sequence, $\frac{i-0.5}{n}$

$\frac{1-0.5}{4}=0.125, \frac{2-0.5}{4}=0.375, \frac{3-0.5}{4}=0.625, \frac{4-0.5}{4}=0.875$

Step 3: Calculate the normal distribution quantiles of the order statistic

$Z(0.125)=-1.15035, Z(0.375)=-0.31864, Z(0.625)=0.31864, Z(0.875)=1.15035$

Step 4: Plot the data against the corresponding normal distribution theoretical quantiles. If the data is normally distributed, the observations should be fitted in a straight line (shown in Figure S6).

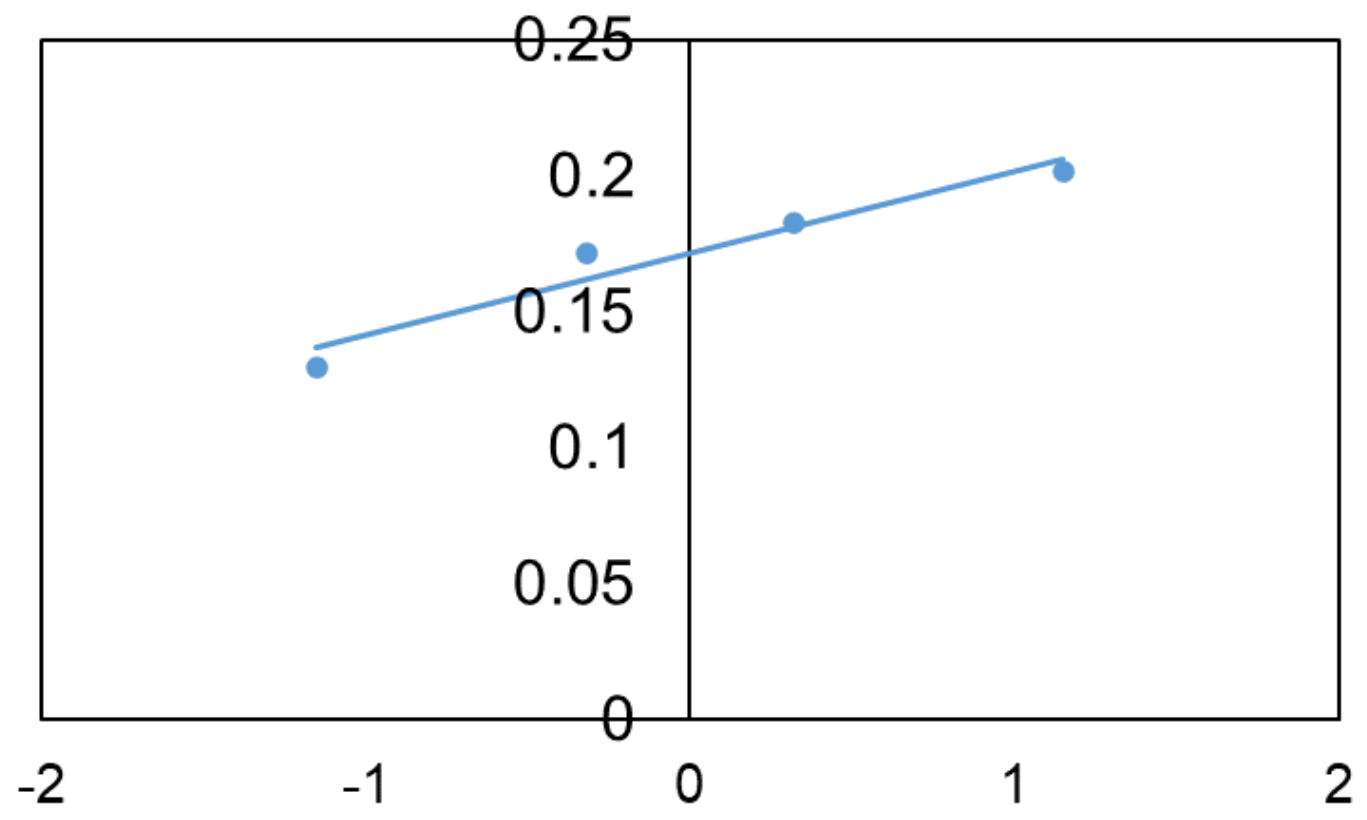

Figure S6. Q-Q plot 
7. Student's two sample t-test

Table S8. Summary of student's two sample t-test results

\begin{tabular}{|c|c|c|}
\hline Compounds & GAC & Pairs showing significant difference \\
\hline \multirow{11}{*}{ MIB } & GAC1 & All vs. Bottom, Top vs. Bottom, Middle vs. Bottom \\
\hline & GAC2 & No pairs \\
\hline & GAC3 & No pairs \\
\hline & GAC4 & No pairs \\
\hline & GAC5 & No pairs \\
\hline & GAC6 & No pairs \\
\hline & GAC7 & All vs. Bottom, Top vs. Bottom, Middle vs. Bottom \\
\hline & GAC8 & $\begin{array}{l}\text { All vs. Top, All vs. Middle, Top vs. Bottom, Top } \\
\text { vs. Middle, Middle vs. Bottom }\end{array}$ \\
\hline & GAC9 & All vs. Top, Top vs. Middle, Top vs. Bottom \\
\hline & GAC10 & No pairs \\
\hline & GAC1 & All vs. Bottom, Top vs. Bottom, Middle vs. Bottom \\
\hline \multirow[t]{3}{*}{ Sucralose } & GAC2 & No pairs \\
\hline & GAC3 & No pairs \\
\hline & GAC1 & No pairs \\
\hline \multirow[t]{3}{*}{ Carbamazepine } & GAC2 & No pairs \\
\hline & GAC3 & All vs. Top, Top vs. Middle, Top vs. Bottom \\
\hline & GAC1 & All vs. Bottom, Top vs. Bottom, Middle vs. Bottom \\
\hline \multirow[t]{10}{*}{ Geosmin } & GAC2 & No pairs \\
\hline & GAC3 & No pairs \\
\hline & GAC4 & No pairs \\
\hline & GAC5 & No pairs \\
\hline & GAC6 & All vs. Top, Top vs. Middle, Top vs. Bottom \\
\hline & GAC7 & All vs. Bottom, Top vs. Bottom, Middle vs. Bottom \\
\hline & GAC8 & $\begin{array}{l}\text { All vs. Top, All vs. Middle, Top vs. Bottom, Top } \\
\text { vs. Middle, Middle vs. Bottom }\end{array}$ \\
\hline & GAC9 & All vs. Top, Top vs. Middle, Top vs. Bottom \\
\hline & GAC10 & No pairs \\
\hline & GAC1 & All vs. Bottom, Top vs. Bottom, Middle vs. Bottom \\
\hline \multirow[t]{3}{*}{ Caffeine } & GAC2 & No pairs \\
\hline & GAC3 & No pairs \\
\hline & GAC1 & No pairs \\
\hline \multirow[t]{2}{*}{ Acetaminophen } & GAC2 & No pairs \\
\hline & GAC3 & All vs. Top, Top vs. Middle, Top vs. Bottom \\
\hline
\end{tabular}


8. The results for adsorption kinetic parameters at each of the 3 different depths
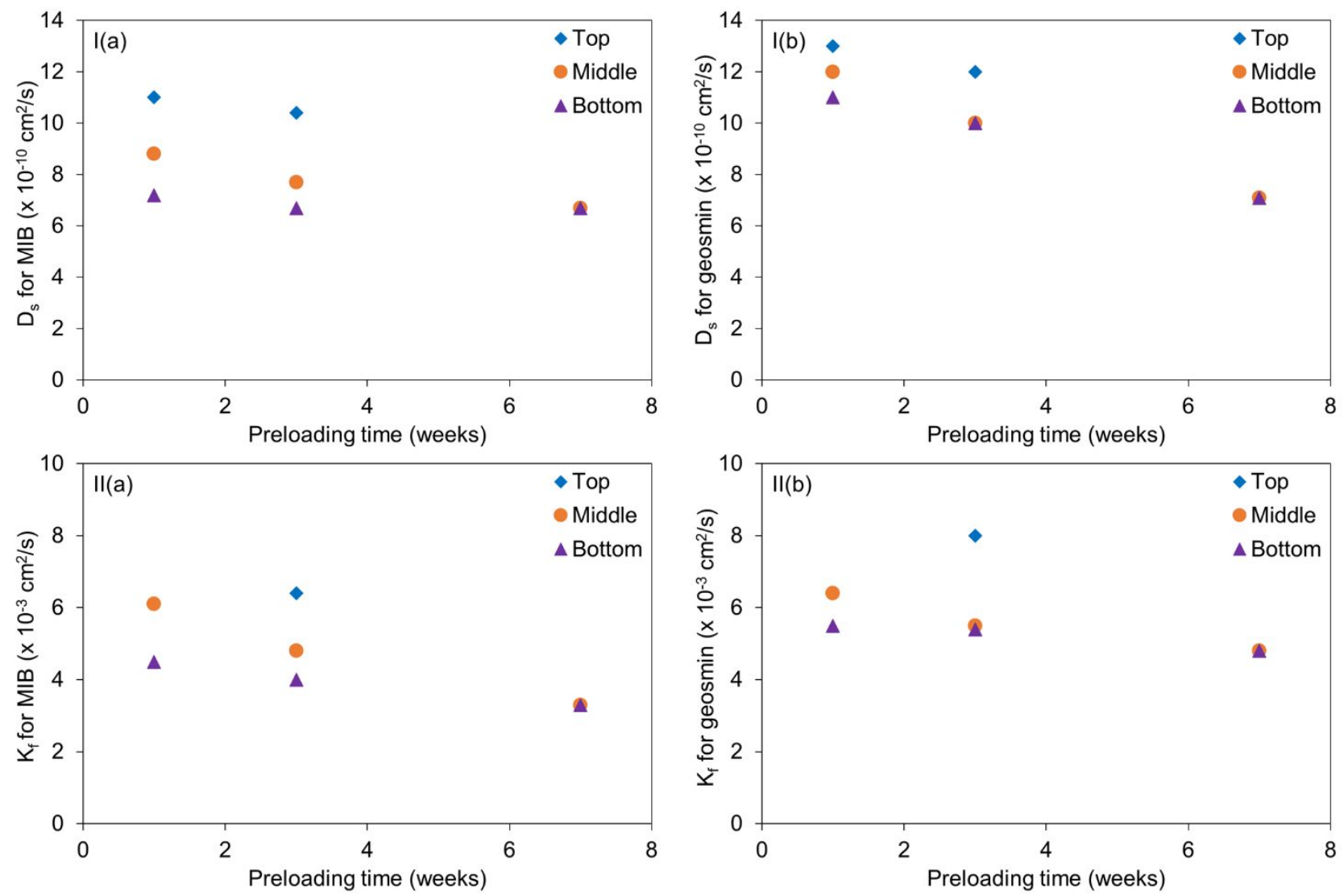

Figure S7. The effect of GAC preloading time on the adsorption kinetic parameters (I) $D_{S}$ and (II) $K_{f}$ for (a) MIB and (b) geosmin at three different filter depths. $K_{f}$ for top GAC at the preloading time of one week cannot be obtained due to zero breakthrough. 
9. Progression of GAC saturation across the filter bed during the first 7 weeks of operation

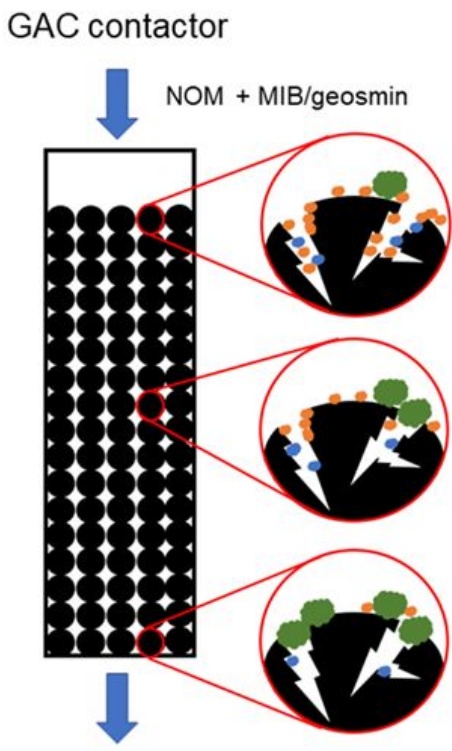

one week

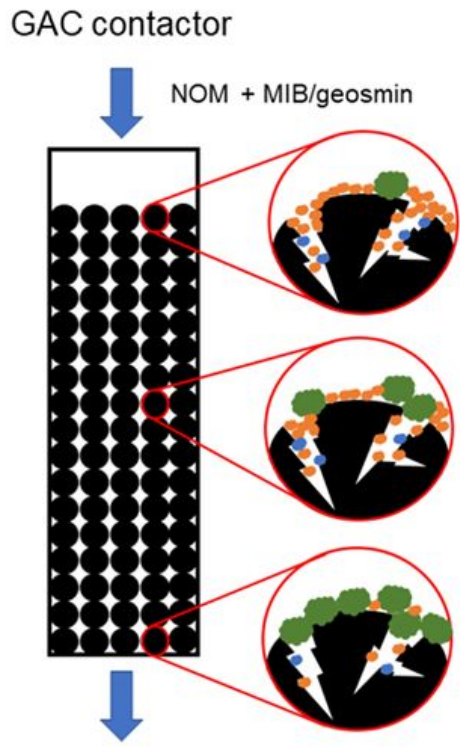

three weeks

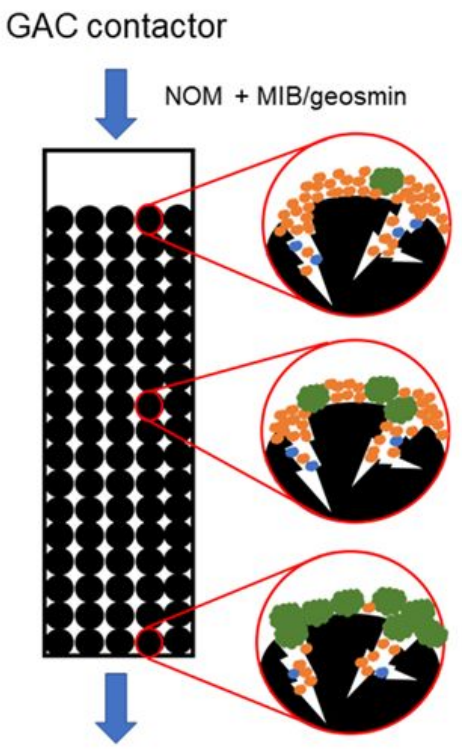

seven weeks

- MIB/geosmin

Large size NOM

Figure S8. Illustration for the progression of GAC saturation across the filter bed during the first 7 weeks of operation

10. Predicted EBCT of the MTZ 


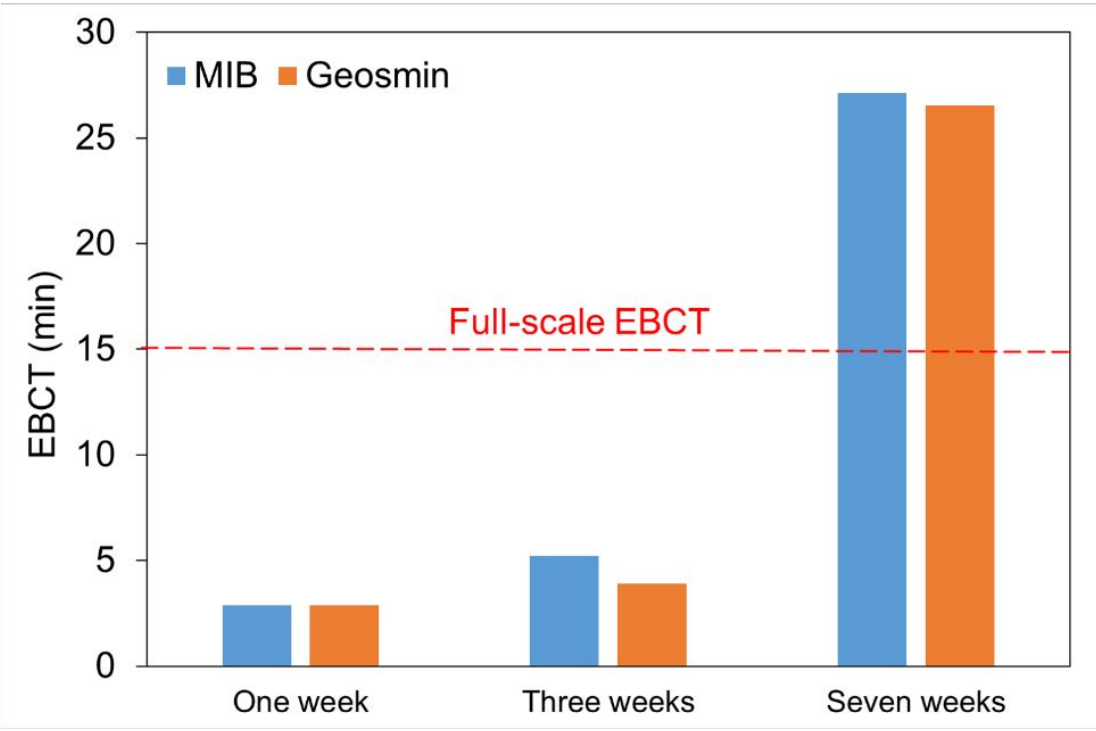

Figure S9. Predicted EBCT of the MTZ using the HSDM for MIB and geosmin in the fullscale GAC contactor during the first 7 weeks

8. ATP level in GAC

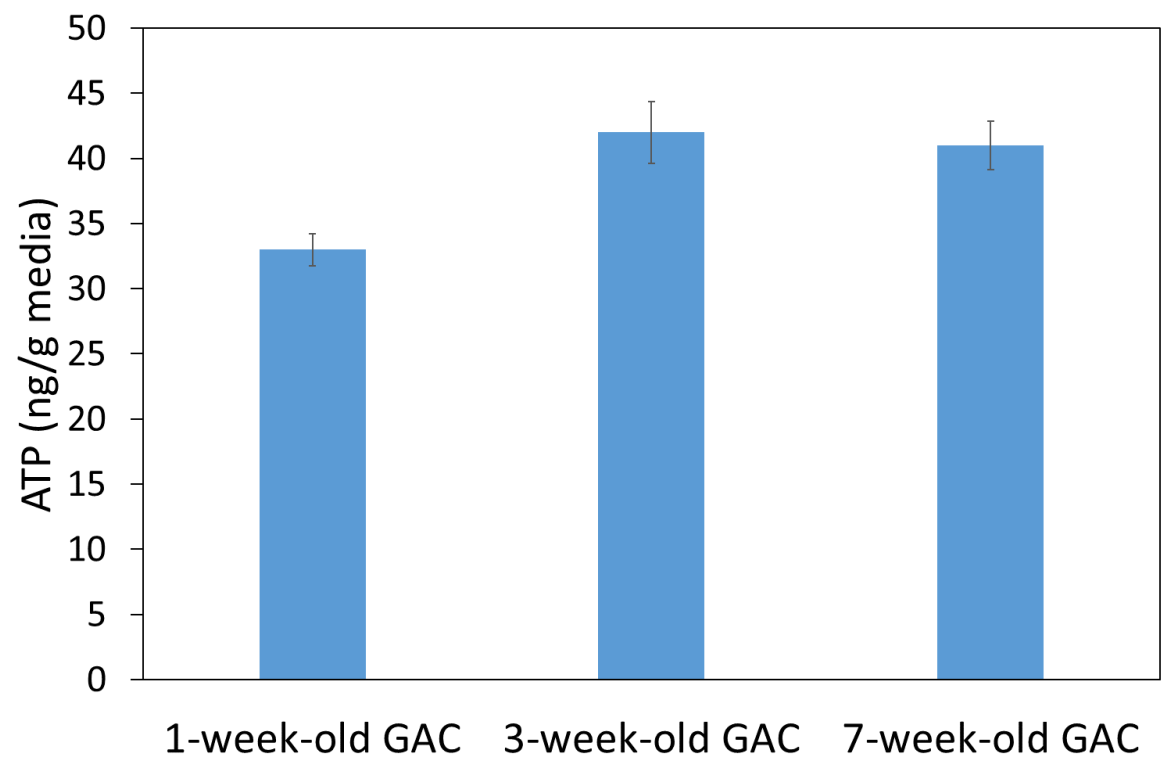

Figure S10. ATP level in 1-week-old, 3-week-old, and 7-week-old Plant C GAC 
References

ACD/Labs Percepta Platform, 2020. Predict Molecular Properties-Physicochemical, ADME \& Tox-from Chemical Structure. https:/www.acdlabs.com/products/percepta/index.php (accessed on Feb. 13, 2021).

Crittenden, J.C., Hand, D.W., Arora, H., Lykins, B.W. Jr., 1987. Design Considerations of GAC Treatment of Organic Chemicals. J. Am Water Works Assoc. 79(1), 74-82.

Graham, M.R., Summers, R.S., Simpson, M.R., Macleod, B.W., 2000. Modeling equilibrium adsorption of 2-methylisoborneol and geosmin in natural waters. Water Res. 34(8), 2291-2300.

Hand, D.W., Crittenden, J.C., Thacker, W.E., 1984. Simplified Models for Design of FixedBed Adsorption Systems. J. Environ. Eng. 110(2), 440-456.

Hayduk, W., Laudie, H., 1974. Prediction of Diffusion Coefficients for Nonelectrolytes in Dilute Aqueous Solutions. AIChE J. 20(3), 611-615.

Howard, P. H., Meylan, W. M., 1997. Handbook of Physical Properties of Organic Chemicals. Lewis Publishers.

Huang, Y., Nie, Z., Yuan, J., Murray, A., Woods-Chabane, G., Hofmann, R., 2019. Experimental validation of a test to estimate the remaining adsorption capacity of granular activated carbon for taste and odour compounds. Environ. Sci.: Water Res. 5, 609-617.

Smith, E.H., 1997. Wave front analysis for design of fixed-bed adsorbers. Chem. Eng. Commun. 159(1), 17-37.

Sontheimer, H., Crittenden, J.C., Summers, R.S., 1988. Activated Carbon for Water Treatment (2nd ed.). Karlsruhe, Germany: DVGW-Forschungsstelle.

Vagliasindi, F., Hendricks, D.W., 1992. Wave Front Behavior in Adsorption Reactors. J. 
Environ. Eng. 118 (4), 530-550.

Young, W.F., Horth, H., Crane, R., Ogden, T., Arnott, M., 1996. Taste and odour threshold concentrations of potential potable water contaminants. Water Res. 30(2), 331-340.

Yuan, J., Huang, Y., Nie, Z., Hofmann, R., 2020. The effect of water temperature on the removal of 2-methylisoborneol and geosmin by preloaded granular activated carbon. Water Res. 183, 116065. 